A study of co-authorship and collaborative research among Indian space technologists

\title{
A study of co-authorship and collaborative research among Indian space technologists"
}

\author{
M S Sridhar
}

\section{Abstract}

The paper sets out the methodology adapted and the sample studied, analyses the productivity of space scientists and engineers in terms of number of papers published with full as well as fractional authorship credits, discusses in detail the pattern of collaboration of space technologists in publishing papers, and lastly, identifies nonintersecting informal communication groups and 'communication stars' based on collaboration.

\section{INTRODUCTION}

The extent of multiple authorship or coauthorship in published papers depends on many factors such as nature of research, nature of financial support, interdisciplinary and heterogeneous nature of the subject, need for team work, informal networks among research workers and so on. It is often presumed that multiple authorship in a paper is a direct consequence of collaborative research of the authors in a group or team. Similarly, the productivity of research workers, especially those in the areas of social, behavioural and pure sciences, is assessed by the number of papers published in reputed journals. An attempt is made here to study the 'collaboration' in publishing and hence in research and the productivity (in terms of number of papers published) of scientists and engineers of ISRO Satellite Centre (ISAC). Bangalore. It is well known that space research is basically problem and mission-oriented research essentially depending on team work. Further, the space sciences in general and satellite technology in particular are highly interdisciplinary and heterogeneous subjects. Incidentally it may be noted that space research itself is much more than R\&D, and unlike other R \& Ds it does not end up with just publications or patents.

\section{METHODOLOGY, SAMPLE AND LIMITATIONS}

Simple statistical presentation and analysis of productivity and collaboration based on full as well as fractional authorship credits and identification of equivalence classes or nonintersecting clusters of collaborators are made for 224 papers of ISAC scientists and engineers. At least one of the authors in all these papers is from ISAC. For the purpose of this study 'co-authorship' and 'collaboration' are used almost interchangeably and a 'communication star' is one who coauthors or collaborates with more independent authors and author groups. Fractional authorship 
A study of co-authorship and collaborative research among Indian space technologists

credit is based on the following method. Taking a multiple authorship paper as unity, credit to an individual co-author is given on pro-rata basis depending on total number of authors. Thus if a paper is published by four authors each one is credited with $1 / 4$ or 0.25 authorship and a summation of such credits is carried out for all papers in which he is a co-author.

The sample references of papers (i.e. 224) available for study is estimated to represent about $25 \%$ of total papers published by ISAC scientists and engineers. Most of these papers are reprints of articles published in journals and conference proceedings. Very few of them are brief communications to journals, special lectures, radio talks and preprints. Technical reports are excluded from the study.

The concept of 'productivity' is not only debatable but also of less relevance as far as space research is concerned. The sample papers under study are not systematically drawn but consist of whatever papers and references were made available by authors against request.

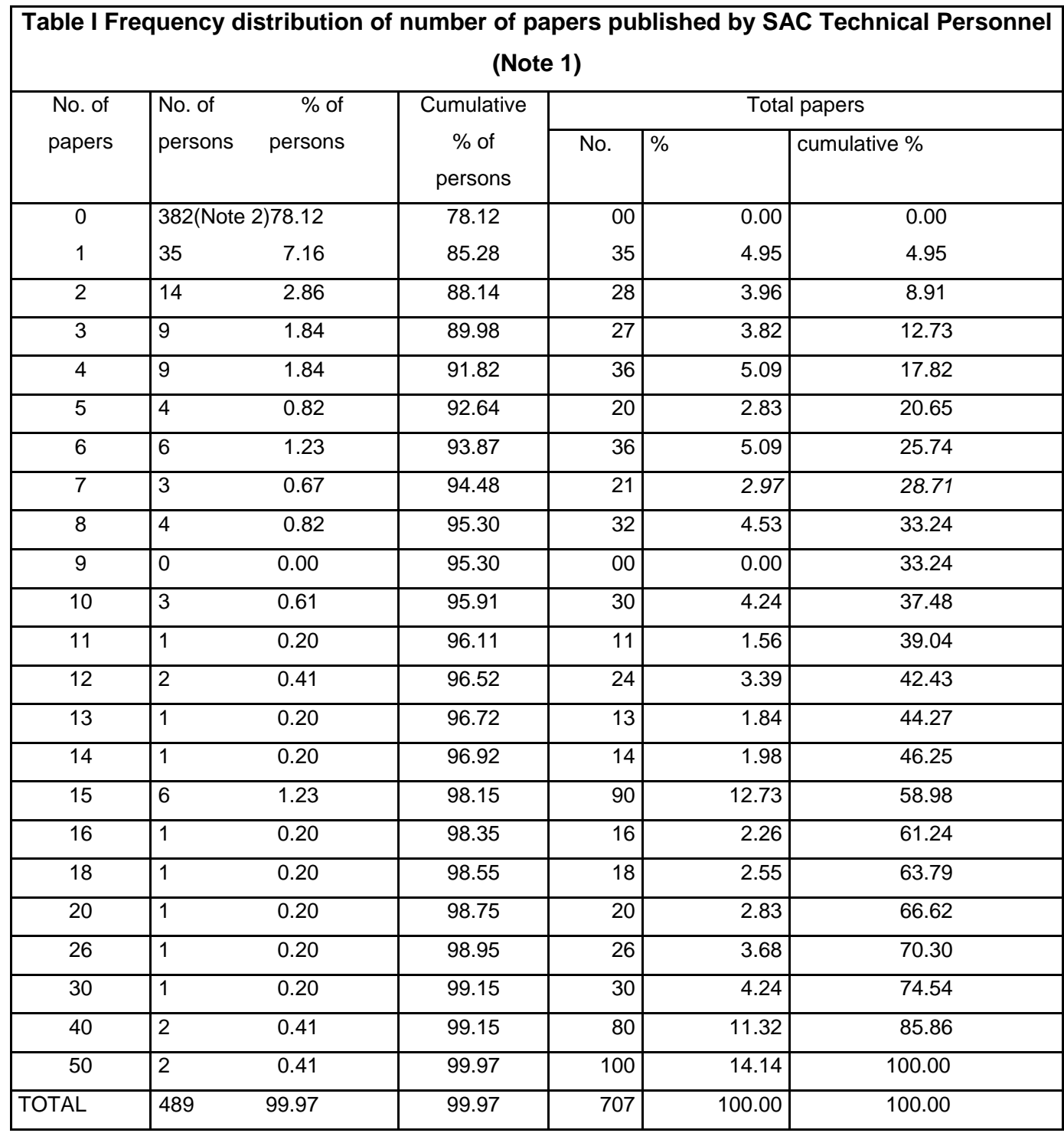

Note 1 This table is based on claims of the authors whereas subsequent tables are based on actual references and papers available in the library.

Note 2 Almost all these persons are other than scientists and engineers (i.e. technical staff at lower levels). 
A study of co-authorship and collaborative research among Indian space technologists

In this connection initially about 800 technical staff (other than medical, transport and library staff and helpers) of ISAC were contacted to know the number of papers published by them. The frequency distribution of 707 papers published by 489 persons who responded is shown in Table 1. Out of the 800 persons contacted nearly 400 were scientists and engineers and the rest lower level technical staff.

\section{PRODUCTIVITY}

A chronological breakdown of papers published by Indian space technologists is depicted in Table 2. The productivity is more or less uniform except for the year 1978 and to some extent for 1975 and 1976. These were years which followed the completion of major projects and there is a weak indication that slightly more papers are published in such years.

Tables 3 and 4 present frequency distribution of productivity of ISAC authors with full credit and coauthors with fractional credit respectively. It may he noted here that 224 papers are authored by 170 different persons, of which 107 are from ISAC. Hence overall average number of papers per author is 1.3.

\begin{tabular}{|c|r|r|c|}
\hline \multicolumn{4}{|c|}{ Table 2: Productivity of Papers } \\
\hline Year & $\begin{array}{l}\text { No. of } \\
\text { papers }\end{array}$ & Percentage & $\begin{array}{c}\text { Cumulative } \\
\text { percentage }\end{array}$ \\
\hline upto 1971 & 71 & 31.7 & 31.7 \\
1972 & 8 & 3.6 & 35.3 \\
1973 & 11 & 4.9 & 40.2 \\
1974 & 9 & 4.0 & 44.2 \\
1975 & 16 & 7.1 & 51.3 \\
1976 & 16 & 7.1 & 58.4 \\
1977 & 7 & 3.1 & 61.5 \\
1978 & 33 & 14.7 & 76.2 \\
1979 & 10 & 4.5 & 80.7 \\
1980 & 12 & 5.4 & 86.1 \\
1981 & 13 & 5.8 & 91.9 \\
1982 & 13 & 5.8 & 97.7 \\
No date & 5 & 2.2 & 99.9 \\
\hline TOTAL & 224 & 99.9 & 99.9 \\
\hline
\end{tabular}

Since there are about 400 scientists and engineers at ISAC, only about one fourth of them have ever published papers.

Table 3 clearly indicates an inverse relationship between productivity and number of authors. For example, $9.3 \%$ of highly productive authors have published $68.0 \%$ of total papers. Similarly, $82.2 \%$ of least productive authors have contributed only $21 \%$ of total papers. Also we may note that the maximum productivity of 146 papers or $28.6 \%$ of total papers is from one author and the second and third highest, respectively, have 64 and 29 papers to their credit. Further, the majority of authors (i.e. 68.2\%) have only one paper to their credit.

It is amply clear from Table 4 that due to high collaboration in publications, the total authorship of 510 in Table 2 comes down to 213 in Table 4 when fractional authorship credit is assigned to co-authors. The productivity of individual authors in this table ranges from 0.1 to 60 . Interestingly, 5 highly productive authors have contributed $50 \%$ of total papers and 85 least productive authors have contributed $31.5 \%$ of total papers. This once again reemphasises the inverse relationship. 
A study of co-authorship and collaborative research among Indian space technologists

\section{COLLABORATION}

Table 5 depicts the extent of collaboration of ISAC authors with others. About 37\% of co-authors of these 224 papers are outsiders. Collaboration with scientists and engineers of other centres and projects of the parent organisation (i.e. ISRO - Indian Space Research Organisation) is only $6 \%$ whereas the collaboration with authors from outside ISRO is about $31 \%$ and it is certainly quite considerable from the angle of study of informal communication networks. However, by deleting 71 papers published previously to the establishment of ISAC (i.e. up to

\begin{tabular}{|c|c|c|c|c|c|c|}
\hline $\begin{array}{c}\text { No. of } \\
\text { papers } \\
\text { (i.e. } \\
\text { productivity) }\end{array}$ & $\begin{array}{c}\text { No. of } \\
\text { Authors }\end{array}$ & $\begin{array}{c}\% \text { of } \\
\text { Authors }\end{array}$ & $\begin{array}{c}\text { Cumulative } \% \\
\text { of } \\
\text { Authors }\end{array}$ & $\begin{array}{c}\text { Total } \\
\text { papers } \\
\text { at credit } \\
\text { (or Authorship) }\end{array}$ & $\begin{array}{c}\% \text { of } \\
\text { papers } \\
\text { at credit }\end{array}$ & $\begin{array}{l}\text { Cumulative } \% \\
\text { of papers } \\
\text { at credit }\end{array}$ \\
\hline 1 & 73 & 68.2 & 68.2 & 73 & 14.3 & 143 \\
\hline 2 & 10 & 9.3 & 77.5 & 20 & 3.9 & 18.2 \\
\hline 3 & 5 & 4.7 & 82.2 & 15 & 2.9 & 21.1 \\
\hline 4 & 2 & 1.9 & 84.1 & 8 & 1.6 & 22.7 \\
\hline 5 & 1 & 0.9 & 85.0 & 5 & 1.0 & 23.7 \\
\hline 6 & 1 & 0.9 & 85.9 & 6 & 1.2 & 24.9 \\
\hline 7 & 1 & 0.9 & 86.8 & 7 & 1.4 & 26.3 \\
\hline 8 & 1 & 0.9 & 87.7 & 8 & 1.6 & 27.9 \\
\hline 9 & 1 & 0.9 & 88.6 & 9 & 1.8 & 29.7 \\
\hline 10 & 1 & 0.9 & 89.5 & 10 & 2.0 & 31.7 \\
\hline 11 & 1 & 0.9 & 90.4 & 11 & 2.2 & 33.9 \\
\hline 12 & 0 & 0.0 & 90.4 & 0 & 0.0 & 33.9 \\
\hline 13 & 3 & 2.8 & 93.2 & 39 & 7.6 & 41.5 \\
\hline 14 & 2 & 1.9 & 95.1 & 28 & 5.5 & 47.0 \\
\hline 75 & 2 & 1.9 & 97.0 & 30 & 5.9 & 52.9 \\
\hline 29 & 1 & 0.9 & 97.9 & 29 & 5.7 & 58.6 \\
\hline 64 & 1 & 0.9 & 98.8 & 64 & 12.6 & 71.2 \\
\hline 146 & 1 & 0.9 & 99.7 & 146 & 28.6 & 99.8 \\
\hline TOTAL & 107 & 99.7 & 99.7 & 510 & 99.8 & 99.8 \\
\hline
\end{tabular}

Note 1: All ISAC authors are given toll credit in this table even if the paper was co-authored. See table 4 for corresponding table in which fractional credits based on number of co-authors are recorded.

1971) the number of outside collaborators comes down to 27 (i.e. 19.4\%). Similarly, the number of co-authors from other centres and projects of ISRO comes down to 7 and total ISAC authors themselves become 105. A cursory look at the outside collaborators reveals that a good majority of them are counterparts in other organisations, one-time colleagues and research guides of ISAC authors. It is not surprising that an almost negligible proportion of the outside collaborators are foreign nationals.

Table 6 presents frequency distribution of collaboration or multiple authorship. Assuming that collaboration in publishing is a result of collaborative research, the data in Table 6 indicate the small size of research teams. The following observations can be made on the data. Only about 
A study of co-authorship and collaborative research among Indian space technologists

$19 \%$ of the papers are single authored. This comes down considerably if we exclude brief communications, special lectures, radio talks and the like which are mostly single authored papers. Thus more than $80 \%$ of papers have two or more authors. The maximum number of authors per paper is ten. Three-authored papers are the most frequent (i.e. 53). About $46.5 \%$ of papers are either two- or three-authored papers. The number of papers steadily decreases as number of authors per paper increases. By and large, the data indicate high collaboration in space research confirming the fact that team work in time-bound projects is one of the important features of space research.

Table 4: Frequency distribution of productivity with fractional authorship credit (for ISAC authors only)

\begin{tabular}{|l|l|l|l|l|l|l|}
\hline $\begin{array}{l}\text { No. of papers } \\
\text { (i.e. Productivity } \\
\text { Range) }\end{array}$ & $\begin{array}{l}\text { No. of } \\
\text { Authors }\end{array}$ & $\begin{array}{l}\text { \% of } \\
\text { Authors }\end{array}$ & $\begin{array}{l}\text { Cumulative } \\
\text { Authors }\end{array}$ & $\begin{array}{l}\text { Total } \\
\text { papers at credit// } \\
\text { Authorship } \\
\text { based on mean }\end{array}$ & $\begin{array}{l}\text { papers } \\
\text { at credit }\end{array}$ & $\begin{array}{l}\text { Cumulative } \\
\% \text { of } \\
\text { papers at } \\
\text { credit }\end{array}$ \\
\hline $0.00-0.25$ & 62 & 57.9 & 57.9 & 10.85 & 5.1 & 5.1 \\
\hline $0.25-0.50$ & 13 & 12.2 & 70.1 & 48.75 & 22.9 & 28.0 \\
\hline $0.50-1.00$ & 10 & 9.4 & 79.5 & 7.50 & 3.5 & 31.5 \\
\hline $1-2$ & 9 & 8.4 & 87.9 & 13.50 & 6.3 & 37.8 \\
\hline $2-3$ & 4 & 37 & 91.6 & 10.00 & 4.7 & 42.5 \\
\hline $3-4$ & 2 & 1.7 & 93.3 & 7.00 & 3.3 & 45.8 \\
\hline $4-5$ & 2 & 1.7 & 95.0 & 9.00 & 4.2 & 50.0 \\
\hline $5-6$ & 0 & 0.0 & 95.0 & 0.00 & 0.0 & 50.0 \\
\hline $6-7$ & 1 & 0.9 & 95.9 & 6.50 & 3.1 & 53.1 \\
\hline $7-8$ & 1 & 0.9 & 96.8 & 7.50 & 3.5 & 56.6 \\
\hline $8-9$ & 1 & 0.9 & 97.7 & 8.50 & 4.0 & 60.6 \\
\hline $24-25$ & 1 & 0.9 & 98.6 & 24.50 & 11.5 & 72.1 \\
\hline $59-60$ & 1 & 0.9 & 99.5 & 59.50 & 27.9 & 100.0 \\
\hline TOTAL & 107 & 99.5 & 99.5 & 213.10 & 100.0 & 100.0 \\
\hline & & & & & & \\
\hline
\end{tabular}

Table 5: Extent of collaboration with outsiders

\begin{tabular}{|l|l|l|}
\hline Author Affiliation & No. & $\%$ \\
\hline ISAC & 107 & 63 \\
Other Centres and Projects of ISRO & 10 & 6 \\
Outside ISRO & 53 & 31 \\
\hline TOTAL & 170 & 100 \\
\hline
\end{tabular}

Lastly, when the broad specialisation or subject backgrounds of co-authors of the individual papers are examined, it is noticed that most of the specialised papers have been authored by persons with the same specialisation and hence a sort of division of work took place among specialists. On the other hand, system level papers are authored by persons with different subject backgrounds. 
A study of co-authorship and collaborative research among Indian space technologists

\section{INFORMAL COMMUNICATION NETWORKS}

One of the important objectives of a study of collaborative research is identification of informal communication networks, communication stars among research workers and size, nature and structure of informal groups. In order to determine the nonintersecting clusters or equivalence classes of collaborators the relationship 'collaborator' or 'coauthor' is taken as an equivalence relationship. If $A$ and $B$ are co-authors in at least one of the papers under study the relation 'A co-authored or collaborated with B' holds good'. By applying the 'co-author' relationship successively for 107 ISAC authors twelve mutually exclusive groups of authors have been identified. The sizes of these groups with their group productivities are presented in table 7.

The first group consists of persons with the broad subject background of physics including astrophysics, electronics, communication engineering, computer science, etc. The second

Table 6: Frequency distribution of collaboration

\begin{tabular}{|c|c|c|c|c|c|c|}
\hline $\begin{array}{l}\text { No. of Authors } \\
\text { per paper }\end{array}$ & $\begin{array}{l}\text { No. of } \\
\text { papers }\end{array}$ & $\begin{array}{c}\% \text { of Total } \\
\text { papers }\end{array}$ & $\begin{array}{c}\text { Cumulative } \\
\% \text { of total } \\
\text { papers }\end{array}$ & $\begin{array}{c}\text { Total } \\
\text { Authorships }\end{array}$ & $\begin{array}{c}\% \text { of } \\
\text { Authorships }\end{array}$ & $\begin{array}{l}\text { Cumulative } \\
\% \text { of } \\
\text { Authorships }\end{array}$ \\
\hline 1 & 43 & 19.2 & 19.2 & 43 & 6.0 & 6.0 \\
\hline 2 & 51 & 22.8 & 42.0 & 102 & 14.3 & 20.3 \\
\hline 3 & 53 & 23.7 & 65.7 & 159 & 22.4 & 42.7 \\
\hline 4 & 30 & 13.4 & 79.1 & 120 & 16.9 & 59.6 \\
\hline 5 & 19 & 8.5 & 87.6 & 95 & 13.4 & 73.0 \\
\hline 6 & 15 & 6.7 & 94.3 & 90 & 12.7 & 85.7 \\
\hline 7 & 6 & 2.7 & 97.0 & 42 & 5.9 & 91.6 \\
\hline 8 & 4 & 1.8 & 98.8 & 32 & 4.5 & 96.1 \\
\hline 9 & 2 & 0.9 & 99.7 & 18 & 2.5 & 98.6 \\
\hline 10 & 1 & 0.4 & 100.1 & 10 & 1.4 & 100.0 \\
\hline TOTAL & 224 & 100.1 & 100.1 & 711 & 100.0 & 100.0 \\
\hline
\end{tabular}

group also consists of persons with almost similar specialisations except astronomy and astrophysics. However, this group has specialists from mechanical engineering, electrical engineering and control engineering also. Most of the other groups have specialists from one or two areas.

It is clear from the table that there are two large groups and all the remaining groups are smaller ones with number of members ranging from 1 to 9 . However, the total group productivity (based on fractional authorship credit) of any small group does not exceed one paper (except group no. 6 which has a productivity of two papers). In other words, almost all highly productive authors are embraced in two large groups. Hence from the point of view of informal communication these two groups deserve more attention than others. It is expected that the members of these groups have access to a wider variety of information through informal networks than others. A further observation of these groups has indicated the following. Highly productive authors have acted as interlinking nodal points in the large groups. Hence most of highly productive authors in these two large groups could be considered as communication stars. There appears to be considerable horizontal or interdivision/ interproject collaboration in research and publications. In other words, the members of these groups cut across the formal organisation barriers such as division, section and project. 
Table 7: Equivalence classes or nonintersecting clusters of collaborators (for ISAC authors only)

\begin{tabular}{|c|c|c|c|c|c|c|c|c|}
\hline \multirow{2}{*}{$\begin{array}{l}\text { Group } \\
\text { No. }\end{array}$} & \multicolumn{2}{|c|}{ Total Authors } & \multicolumn{3}{|c|}{ Productivity with full Authorship } & \multicolumn{3}{|c|}{ Productivity with fractional Authorship } \\
\hline & No. & $\%$ & No. & $\%$ & Cumulative \% & No. & $\%$ & Cumulative \% \\
\hline 1 & 41 & 38.3 & 352 & 69.0 & 69.0 & 118.13 & 67.8 & 67.8 \\
\hline 2 & 29 & 27.1 & 119 & 23.3 & 92.3 & 45.97 & 26.5 & 94.3 \\
\hline 3 & 9 & 8.4 & 9 & 1.8 & 94.1 & 1.00 & 00.6 & 94.9 \\
\hline 4 & 8 & 7.5 & 8 & 1.6 & 95.7 & 1.00 & 00.5 & 95.4 \\
\hline 5 & 6 & 5.6 & 6 & 1.2 & 96.9 & 1.00 & 00.6 & 96.0 \\
\hline 6 & 5 & 4.7 & 6 & 1.2 & 98.1 & 2.00 & 01.2 & 91.2 \\
\hline 7 & 2 & 1.9 & 2 & 0.4 & 98.5 & 1.00 & 00.6 & 97.8 \\
\hline 8 & 2 & 1.9 & 3 & 0.6 & 99.1 & 1.50 & 00.9 & 98.7 \\
\hline 9 & 2 & 1.9 & 2 & 0.4 & 99.5 & 0.22 & 00.1 & 98.8 \\
\hline 10 & 1 & 0.9 & 1 & 0.2 & 99.7 & 1.00 & 00.6 & 99.4 \\
\hline 11 & 1 & 0.9 & 1 & 0.2 & 99.9 & 1.00 & 00.6 & 100.0 \\
\hline 12 & 1 & 0.9 & 1 & 0.2 & 100.1 & 1.00 & 00.6 & 100.6 \\
\hline TOTAL & 107 & 100.00 & 510 & 100.1 & 100.1 & 174.32 & 100.6 & 100.6 \\
\hline
\end{tabular}

Table 8: Collaboration of highly productive authors

\begin{tabular}{|c|c|c|c|c|c|c|c|c|c|c|c|}
\hline \multirow{2}{*}{$\begin{array}{l}\text { SI. } \\
\text { No. }\end{array}$} & \multicolumn{5}{|c|}{ Productivity (Authorship) } & \multirow{2}{*}{$\begin{array}{c}\text { Gross } \\
\text { No.of } \\
\text { colla- } \\
\text { borators } \\
\text { (Note 1) }\end{array}$} & \multirow{2}{*}{$\begin{array}{c}\text { Net } \\
\text { No.of } \\
\text { colla- } \\
\text { borators } \\
\text { (Note 2) }\end{array}$} & \multicolumn{2}{|c|}{$\begin{array}{c}\text { Average } \\
\text { Productivity of } \\
\text { authors in the } \\
\text { group } \\
\end{array}$} & \multirow{2}{*}{$\begin{array}{c}\text { Av.no.of } \\
\text { authors } \\
\text { per } \\
\text { paper } \\
\text { col (7) / } \\
\text { col (6) }\end{array}$} & \multirow{2}{*}{ 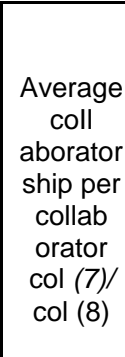 } \\
\hline & $\begin{array}{l}\text { With } \\
\text { frac- } \\
\text { tional } \\
\text { credit }\end{array}$ & $\begin{array}{l}\text { With full } \\
\text { credit }\end{array}$ & $\begin{array}{l}\text { Single } \\
\text { Authored } \\
\text { papers }\end{array}$ & $\begin{array}{l}\text { Fractional } \\
\text { credit }\end{array}$ & $\begin{array}{c}\text { Papers } \\
\text { with } 2 \text { or } \\
\text { more } \\
\text { authors }\end{array}$ & & & $\begin{array}{l}\text { Fractional } \\
\text { credit col } \\
\text { (5)/ col (8) }\end{array}$ & $\begin{array}{l}\text { Full } \\
\text { credit } \\
\text { col (6) } \\
\text { / col } \\
(8)\end{array}$ & & \\
\hline 1 & 2 & 3 & 4 & 5 & 6 & 7 & 8 & 9 & 10 & 11 & \begin{tabular}{|l|}
12 \\
\end{tabular} \\
\hline 1 & 59.71 & 146 & 20 & 39.71 & 126 & 343 & 41 & 0.95 & 3.00 & 2.72 & 8.37 \\
\hline 2 & 24.58 & 64 & 8 & 16.50 & 56 & 168 & 30 & 0.53 & 1.81 & 3.00 & 5.60 \\
\hline 3 & 6.14 & 29 & 0 & 6.14 & 29 & 171 & 25 & 0.24 & 1.12 & 5.90 & 6.64 \\
\hline 4 & 3.29 & 15 & 0 & 3.29 & 15 & 56 & 8 & 0.37 & 1.67 & 3.73 & 7.00 \\
\hline 5 & 4.98 & 15 & 0 & 4.98 & 15 & 43 & 11 & 0.42 & 1.25 & 2.87 & 3.91 \\
\hline 6 & 2.07 & 14 & 0 & 2.07 & 14 & 57 & 16 & 0.16 & 0.82 & 4.07 & \begin{tabular}{|l|}
3.56 \\
\end{tabular} \\
\hline 7 & 4.03 & 14 & 0 & 4.03 & 14 & 40 & 12 & 0.29 & 1.08 & 2.86 & 3.33 \\
\hline 8 & 7.05 & 13 & 4 & 3.05 & 9 & 16 & 11 & 0.29 & 0.75 & 1.78 & 1.45 \\
\hline 9 & 2.95 & 13 & 0 & 2.95 & 13 & 49 & 11 & 0.25 & 1.08 & 3.77 & 4.45 \\
\hline 10 & 8.83 & 13 & 6 & 2.83 & 7 & 12 & 7 & 0.35 & 0.88 & 1.71 & 1.71 \\
\hline $\begin{array}{l}\text { MEAN } \\
\text { TOTAL }\end{array}$ & 124.98 & 336 & 38 & 86.98 & 298 & 955 & 172 & 0.51 & 1.73 & 3.20 & 5.55 \\
\hline
\end{tabular}

Note 1 Total number of co-authors in all the papers in which the given person is also an author. This includes repetitive coauthorship.

Note 2 This ignores repetitive co-authorship and presents number of individuals co-authored with the given person.

Lastly, the presentation in Table 8 tries to probe, from different angles, the collaboration of ten highly productive authors. As could he seen from the table only four of them have written papers without collaborators (see Column 4). Average productivities of the first two authors (see Column 9 and 10) are more than the mean productivity. On the other hand the average number of authors per paper (Column 11) is more than mean in case of 3rd, 4th, 6th and 9th authors. Also the average collaboratorship per collaborator (i.e. Column 12) is very high in case of first four authors indicating thereby more intensive informal exchange of information by these authors with other authors. It is the highly productive authors who are also communication stars playing a key role. The average productivity per author in the groups, average number of 
A study of co-authorship and collaborative research among Indian space technologists

authors per group and finally average collaboratorship per collaborator heavily depended on the contribution of these highly productive communication stars. Thus any information input to the groups/networks at these nodal points (i.e. communication stars) is expected to flow faster and disseminate more widely depending on the above indexes than other points in the communication networks.

\section{CONCLUSION}

In summary, we may note that slightly more papers are published in the year following the completion of major projects, only about one fourth of scientists and engineers at ISAC have the habit of writing and publishing papers, there appears to be an inverse relationship between productivity and the number of authors per paper as less than $10 \%$ of authors have published almost $60 \%$ of papers and $82 \%$ of authors have contributed only $21 \%$ of total papers, majority of authors (i.e. 68\%) have only one paper to their credit, one author published 146 papers or $28.6 \%$ of total papers and five highly productive authors have contributed more than $50 \%$ of total papers.

Further, more than $80 \%$ of papers have two or more authors. There appears to be high collaboration in publishing papers implying high collaboration in space research. Collaboration with authors from outside ISRO is also considerable (i.e. 31\%).

By and large, the study has indicated a low productivity and high collaboration and coauthorship pattern among space technologists. It is also observed that the productivity of papers by scientists is much more than that of engineers. Some of the possible reasons for low productivity are as follows. As mentioned earlier the nature of the organisation is more than just R\&D and the emphasis in the objective is to produce workable satellites in the given time rather than working papers or establishing patents. Among the authors analysed, a good majority of highly productive authors are scientists. Though the centre has more engineers than scientists the number of papers published by scientists is greater than those published by engineers. It is commonly accepted that scientists are more attuned to publishing papers than engineers and the data support this common belief. Further, a considerable number of scientists and engineers in the centre are young and less experienced. They may need a few years of fruitful experience after settling on the job before starting to write papers. On the other hand, high collaboration in publishing papers is clearly the result of the mission-oriented nature of the organisation necessitating high collaboration in work.

The study has identified two large nonintersecting informal communication groups with 65\% of authors contributing 94\% of papers. Many highly productive authors have been identified as communication stars. Lastly, there appears to be considerable horizontal collaboration in publishing papers.

A further detailed study of these and other informal communication groups and channels with 
A study of co-authorship and collaborative research among Indian space technologists

a larger data base and also by other methods is underway.

\section{ACKNOWLEDGMENT}

Author's grateful thanks are due to Shri. H.A. Khan. Reader, Department of Library and Information Science. University of Mysore, Mysore for going through the draft paper and offering valuable suggestions.

\section{NOTE AND REFERENCE}

1. For background details about equivalence relation and equivalence classes any fundamental book on set theory of the first part of the following paper of the author may be seen: 'A Mathematical Approach to Relations in Thesauri', Journal of Library and Information Science, 5(1) June 1980, 77-79.

* R\&D Management 15 (3) July 1985: 243-249.

\section{About the Author}

Dr. M. S. Sridhar is a post graduate in Mathematics and Business Management and a Doctorate in Library and Information Science. He is in the profession for last 36 years. Since 1978, he is heading the Library and Documentation Division of ISRO Satellite Centre, Bangalore. Earlier he has worked in the libraries of National Aeronautical Laboratory (Bangalore), Indian Institute of Management (Bangalore) and University of Mysore. Dr. Sridhar has published 4 books, 83 research articles, 22 conferences papers, written

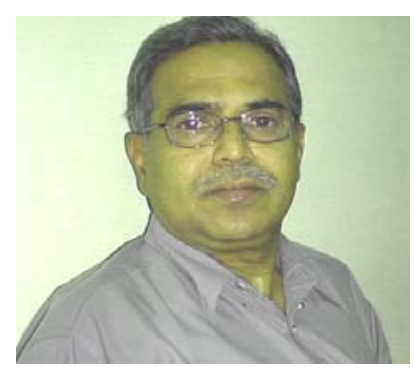
19 course materials for BLIS and MLIS, made over 25 seminar presentations and contributed 5 chapters to books.

E-mail: sridharmirle@yahoo.com, mirlesridhar@gmail.com, sridhar@isac.gov.in ; Phone: 9180-25084451; Fax: 91-80-25084476. 